\title{
Sedimentary deposits of the 26 December 2004 tsunami on the northwest coast of Aceh, Indonesia
}

\author{
Andrew Moore ${ }^{1}$, Yuichi Nishimura ${ }^{2}$, Guy Gelfenbaum ${ }^{3}$, Takanobu Kamataki ${ }^{4}$, and Rahmat Triyono ${ }^{5}$ \\ ${ }^{1}$ Department of Geology, Kent State University \\ ${ }^{2}$ Institute of Seismology and Volcanology, Hokkaido University \\ ${ }^{3}$ U.S. Geological Survey, Coastal and Marine Geology Program \\ ${ }^{4}$ Active Fault Research Center, Geological Survey of Japan, AIST \\ ${ }^{5}$ Badan Meteorologi and Geofisika, Bandung, Indonesia
}

(Received August 8, 2005; Revised January 5, 2006; Accepted January 6, 2006; Online published February 17, 2006)

\begin{abstract}
The 2004 Sumatra-Andaman tsunami flooded coastal northern Sumatra to a depth of over 20 m, deposited a discontinuous sheet of sand up to $80 \mathrm{~cm}$ thick, and left mud up to $5 \mathrm{~km}$ inland. In most places the sand sheet is normally graded, and in some it contains complex internal stratigraphy. Structures within the sand sheet may record the passage of up to 3 individual waves. We studied the 2004 tsunami deposits in detail along a flowparallel transect about $400 \mathrm{~m}$ long, $16 \mathrm{~km}$ southwest of Banda Aceh. Near the shore along this transect, the deposit is thin or absent. Between 50 and $400 \mathrm{~m}$ inland it ranges in thickness from 5 to $20 \mathrm{~cm}$. The main trend in thickness is a tendency to thicken by filling low spots, most dramatically at pre-existing stream channels. Deposition generally attended inundation-along the transect, the tsunami deposited sand to within about $40 \mathrm{~m}$ of the inundation limit. Although the tsunami deposit contains primarily material indistinguishable from material found on the beach one month after the event, it also contains grain sizes and compositions unavailable on the current beach. Along the transect we studied, these grains become increasingly dominant both landward and upward in the deposit; possibly some landward source of sediment was exposed and exploited by the passage of the waves. The deposit also contains the unabraded shells of subtidal marine organisms, suggesting that at least part of the deposit came from offshore. Grain sizes within the deposit tend to fine upward and landward, although individual units within the deposit appear massive, or show reverse grading. Sorting becomes better landward, although the most landward sites generally become poorly sorted from the inclusion of soil clasts. These sites commonly show interlayering of sandy units and soil clast units. Deposits from the 2004 tsunami in Sumatra demonstrate the complex nature of the deposits of large tsunamis. Unlike the deposits of smaller tsunamis, internal stratigraphy is complex, and will require some effort to understand. The Sumatra deposits also show the contribution of multiple sediment sources, each of which has its own composition and grain size. Such complexity may allow more accurate modeling of flow depth and flow velocity for paleotsunamis, if an understanding of how tsunami hydraulics affect sedimentation can be established.
\end{abstract}

Key words: Tsunami deposit, Aceh, 2004 Indian Ocean tsunami.

\section{Introduction}

The 2004 Sumatra-Andaman tsunami represents the first trans-oceanic tsunami in more than 40 years, and the only such tsunami to have been studied other than the 1960 Chilean event. It is also easily the largest since 1960-runups near the source exceed $35 \mathrm{~m}$ (Kamataki and Nishimura, 2005). Although tsunami sedimentation has been studied for several smaller modern tsunamis, including 1992 Flores (Minoura et al., 1997; Shi et al., 1995), 1993 Okushiri (Nishimura and Miyaji, 1995; Sato et al., 1995), 1994 Java (Dawson et al., 1996), and 1998 Papua New Guinea (Gelfenbaum and Jaffe, 2003), few studies have looked at the modern deposits of basin-wide tsunamis, simply because so few have occurred. One such study was carried out for the 1960 Chile tsunami on the Sanriku coast

Copyright (c) The Society of Geomagnetism and Earth, Planetary and Space Sciences (SGEPSS); The Seismological Society of Japan; The Volcanological Society of Japan; The Geodetic Society of Japan; The Japanese Society for Planetary Sciences; TERRAPUB of Japan (Konno, 1961), but only a few words have been written about tsunami deposition by a large tsunami near its source (e.g., Cisternas et al., 2005; Wright and Mella, 1963).

Understanding the sedimentary deposits of large tsunamis close to their source is important because several large paleoseismic events have been recognized based, in part, on their tsunami deposits (e.g., Atwater et al., 2005; Cisternas et al., 2005; Nanayama et al., 2003; Pinegina et al., 2003). Modern examples of these large tsunamis will help not only in providing clues to the recognition of similar paleotsunamis, but also in understanding the hydraulics of deposition by tsunamis so that paleotsunami size may be estimated from the deposits left behind.

\section{The 2004 Earthquake and Tsunami}

At 00:58 UTC on 26 December 2004, an earthquake estimated to between $\mathrm{M}=9.0$ and $\mathrm{M}=9.3$ resulted from a 1300 $\mathrm{km}$-long rupture of the fault boundary between the subducting Indo-Australian Plate and the overriding Burma Plate 

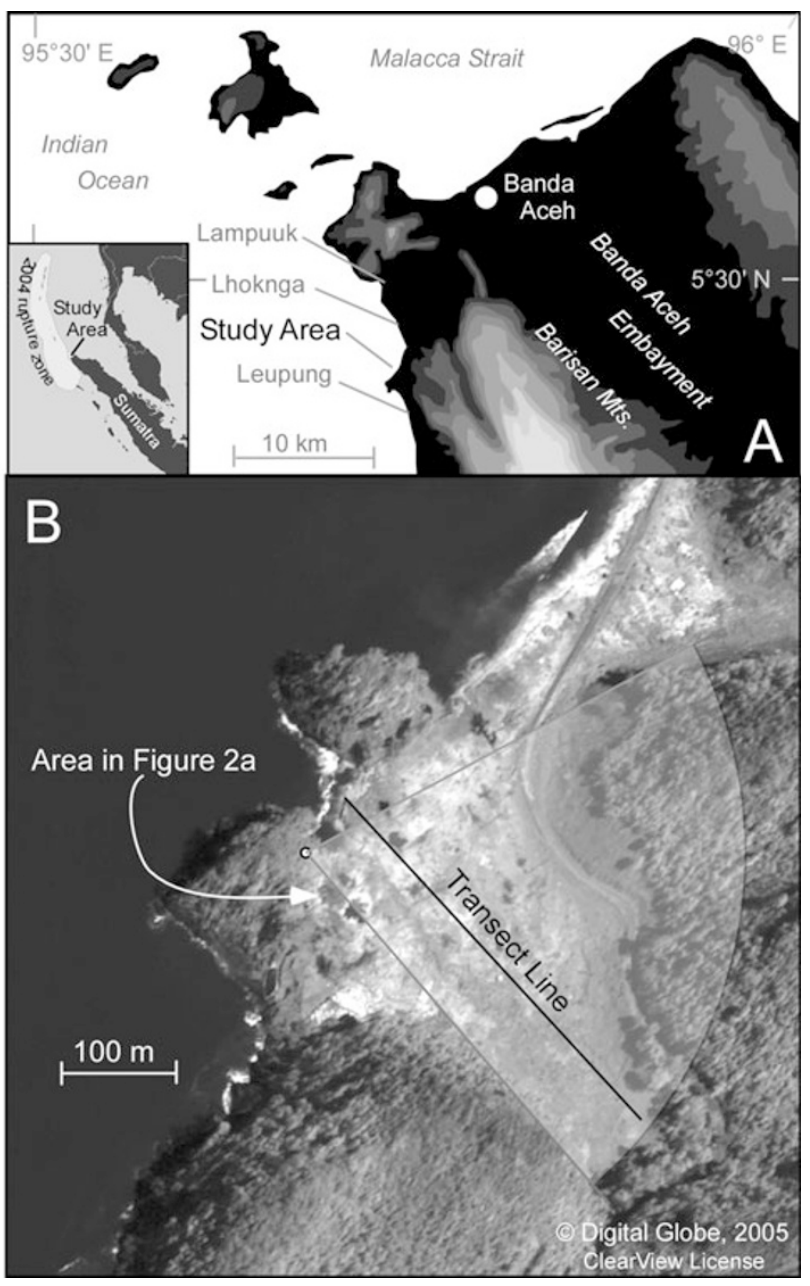

Fig. 1. A. Location map of the area studied near Banda Aceh (after Bennett et al., 1980). Contour interval $\sim 80 \mathrm{~m}$. B. Satellite photo of study area one month after the tsunami, showing approximate line of transect in Fig. 2.

(Tanioka et al., this issue). The accompanying displacement of the sea floor generated a large tsunami that devastated coastal areas around the Indian Ocean, and was measurable worldwide. Tsunamis were also generated during earthquakes farther southeast along this subduction zone in 1861 and 1933 (Hamzah et al., 2000), but the extent of damage from these events is not well known.

An International Tsunami Survey Team composed of tsunami researchers from Japan, the United States, and Indonesia visited northernmost Sumatra from January 20 to 29,2005 , in order to survey the damage caused by the tsunami. The fifteen members formed four teams for study in runup, hydraulics, subsidence, and sedimentology. The sedimentology team wrote this report.

In addition to its specialization, each team estimated flow depth, flow direction, and runup height. The sedimentology team traveled primarily to the southeast of Banda Aceh, from approximately Lampuuk south to Leupung (Fig. 1). The coastline in this area varies; to the north it borders a coastal plain that extends kilometers inland, whereas to the south steep hills extend to the coastline in some areas, or are separated from it by a narrow strip of coastal plain about 300-400 $\mathrm{m}$ wide. In the south, inundation distance was limited because the waves stopped against the hills.

We selected one area, south of Lhoknga, for further study. The area was selected for a number of reasons, including: the presence of a sand sheet visible on satellite images, relatively few buildings to complicate flow patterns, and the presence of abundant flow depth and direction indicators. In this location, we characterized the tsunami sedimentation by establishing a measured transect in the direction of flow, extending from the shoreline to the limit of inundation.

\section{Location}

The transect is located about $16 \mathrm{~km}$ southwest of Banda Aceh and about $3 \mathrm{~km}$ south of Lhoknga, in a small valley between two headlands of the Raba Fm. (Bennett et al., 1980), a sequence of interbedded Mesozoic cherty limestones and shales (Fig. 2(a)-(c)). The headlands stand about $35 \mathrm{~m}$ above the valley at the coast (Figs. 1(b) and 2(d)). The beach between the two headlands was relatively narrow, and was backed by loosely cemented Pleistocene carbonate gravel containing abundant coral fragments and shells. A small resort (the Seaside Resort Hotel) occupied most of the valley.

The tsunami here reached flow depths of more than 25 $\mathrm{m}$, and flowed at speeds estimated up to $10 \mathrm{~m} / \mathrm{s}$ (Kamataki and Nishimura, 2005). The number of waves that struck the area, and how soon after the earthquake the tsunami arrived are not known, because no eyewitnesses survived. However, in Banda Aceh, the closest location where the survey team interviewed eyewitnesses, three large waves struck the coast; it seems plausible that this area was also so struck. Flow was probably focused as it rushed between the headlands, as judged from valley-mouth increases in observed flow depths (Fig. 2(d)).

\section{Methods}

Our measured transect at the former resort originates at the shoreline at $5^{\circ} 26^{\prime} 32.5^{\prime \prime} \mathrm{N} 95^{\circ} 14^{\prime} 22.8^{\prime \prime} \mathrm{E}$. From there it extends $\sim 400 \mathrm{~m}$ inland in the direction of flow, crossing the inland limit of tsunami-deposited sand and continuing another $40 \mathrm{~m}$ inland to the limit of tsunami inundation (Fig. 2(a)). At 40-m intervals along this transect, we measured sediment thickness, described the deposit stratigraphy, and collected samples of sediment for later grain size analysis.

Samples for grain size analysis were dry heated to $140^{\circ} \mathrm{C}$ for 48 hours before analysis. Few organics were present in the sand; large organic debris (grass stems, twigs, etc.) was removed with a forceps. The samples contained almost no silt or clay, and were not rinsed prior to analysis.

We determined grain size within the deposit using a Retsch Camsizer, an optically based instrument capable of determining grain size to within $\pm 1 \%$ over the range $30 \mu \mathrm{m}$ to $30,000 \mu \mathrm{m}$ ( $5 \phi$ to $-5 \phi$ ). The instrument images a falling curtain of sediment at $25 \mathrm{~Hz}$, then determines the grain size of each particle in the image, in our case by determining the cross-sectional area of the particle and then reporting the diameter of a circle of equivalent area. This tends to increase the grain size relative to sieving, but probably yields a result more compatible with settling tube. Because the instrument made between 20 million and 40 million indi- 

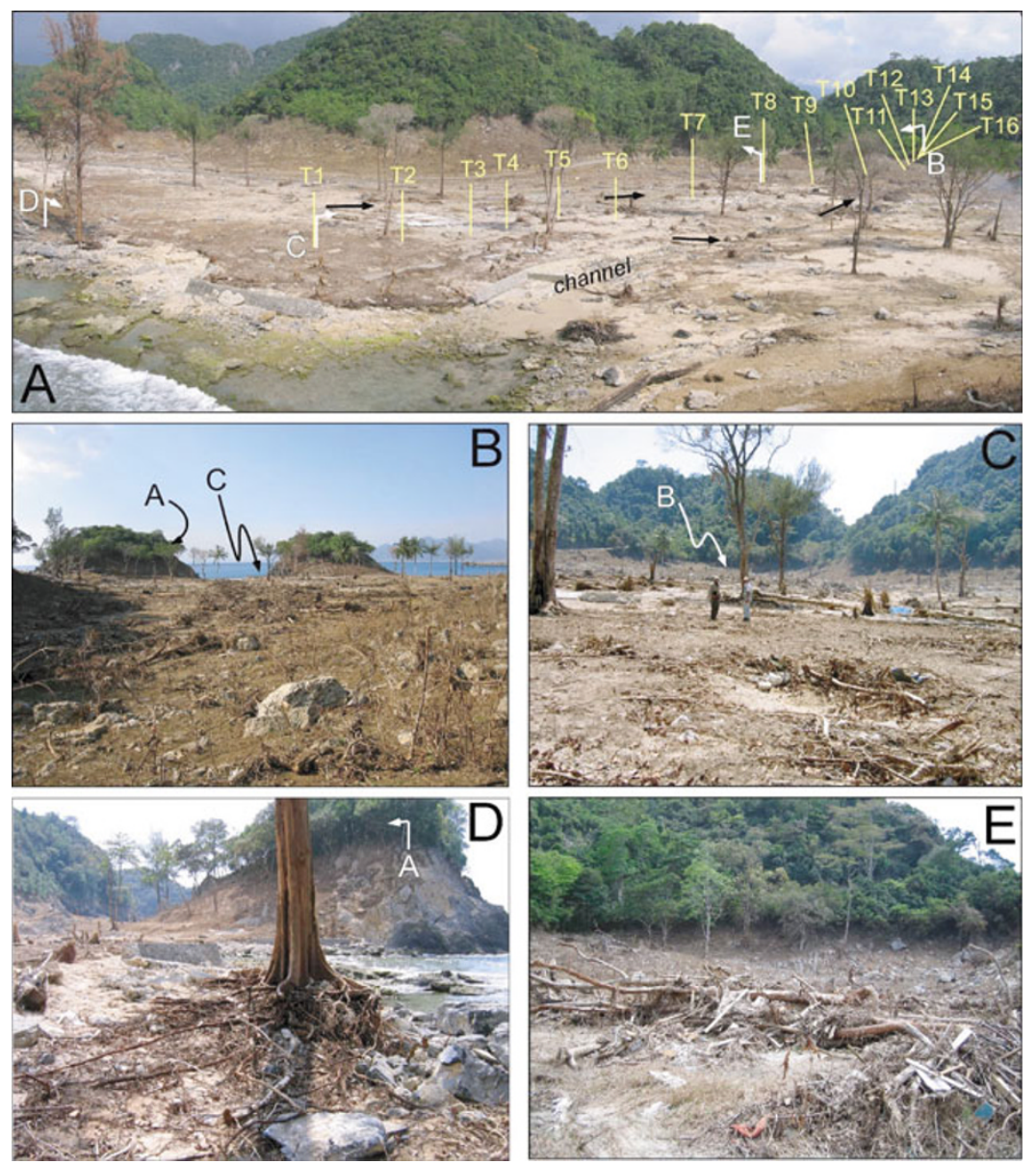

Fig. 2. Views of the sediment transect about one month after the tsunami. White arrows show orientation and location of photos A-E. Black arrows show flow direction inferred from oriented debris. Yellow bars identify the location of each sample location. A. Overview of the area looking northeast. Sea to left. B. View seaward along transect, showing gaps through which water poured, and approximate flow depth from soil stripping on coastal knolls. C. View landward along transect, showing maximum runup at back of valley. Pit in the foreground is the socket remaining where a tree had been removed by tsunami. Stumps in middle ground (near standing people) are remains of trees that the tsunami snapped off near their base. D. Tree roots exposed by tsunami erosion at seaward end of transect. Bark was abraded by debris and sediment in the water. Background shows that water level decreased inland after flowing through the gap shown in B. E. Debris field near landward end of transect. Debris in the field records tsunami inflow and outflow.

vidual measurements on our samples (depending on sample size), the resulting dataset can easily support $1 / 16 \phi$ to $1 / 32$ $\phi$ resolutions.

Sample mean and standard deviation were determined using the method of moments on $1 / 16 \phi$ resolution data from the Camsizer. Median grain size was determined by linear interpolation of the $1 / 16 \phi$ data.

\section{Sediment Description}

The transect shows a progression from intense erosion near coast, deposition of sediment inland, to deposition of sediment and debris near the landward edge of inundation. Along the coastline, the tsunami removed the small $(\sim 10$ $m$ wide) beach visible in satellite images taken before the disaster. The tsunami also removed all soil within at least 20 meters of the shoreline, exposing the roots of trees that withstood the flow and scouring into underlying beach rock. This soil stripping, with little or no sedimentation, continued about 50 meters from the present shoreline (to about "T2" in Figs. 2(a) and 4). In this zone, the tsunami snapped most trees near the base, or removed them with their root balls, leaving a socket where the tree had been (Fig. 2(c)).
The few remaining trees had their bark stripped off and the underlying wood abraded. This stripping and abrasion is commonly greatest on the seaward side, but can extend around the whole trunk (Fig. 2(d)).

About 50 to $200 \mathrm{~m}$ from the beach, sand was deposited in a continuous layer about $10 \mathrm{~cm}$ thick, although the sand ranged from nearly 0 on topographic highs close to the shore, to over $20 \mathrm{~cm}$ thick in local swales. One local depression, a concrete-lined drainage running through the former resort ( $\sim 1 \mathrm{~m}$ deep and $5 \mathrm{~m}$ wide), was so completely filled with sand that it was often indistinguishable from the surrounding ground surface (Fig. 2(a)). More trees remain standing in this area, although the majority were snapped off near the base. Those that remain show signs of abrasion on their trunks, including stripped bark and snapped off branches.

From about $200 \mathrm{~m}$ from shore inland to the edge of inundation (up to about $450 \mathrm{~m}$ from shore), debris such as tree trunks and the contents of houses becomes an increasingly large part of the deposit (Fig. 2(e)). The preservation of rooted grass at the base of the tsunami deposit suggests that in this area, erosion was not intense enough to strip the soil. 

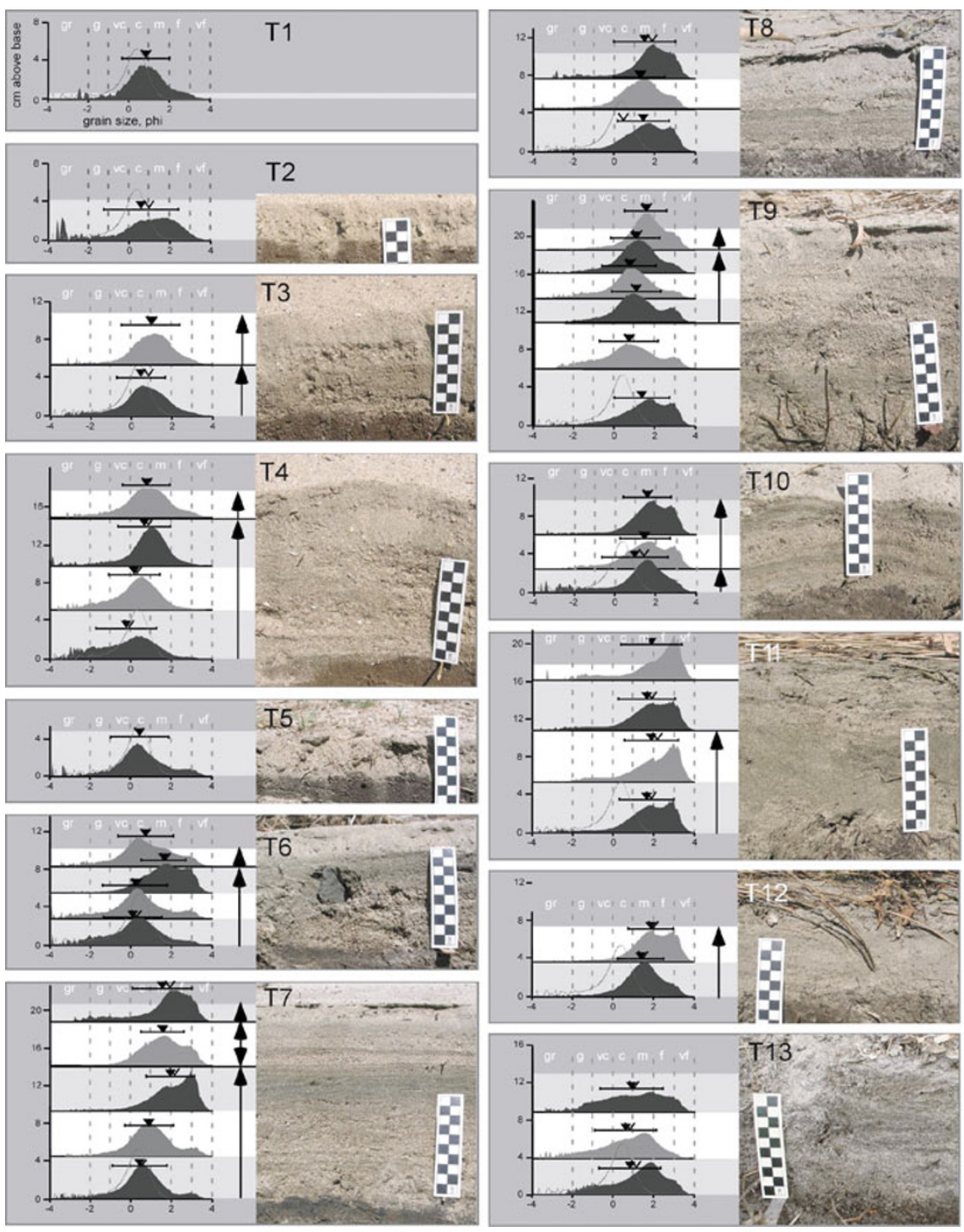

Fig. 3. Grain size profiles along the transect. Each square in photograph scale is $1 \mathrm{~cm}$. All photos are taken perpendicular to the flow direction (and therefore to the transect), with the ocean on the left, and the land on the right. Gray and white rectangles to the left of the photos show the interval sampled for each grain size analysis; the results of each analysis are shown by the histograms in each rectangle. For each analysis, the inverted triangle marks the sample mean, inverted carat the sample median, and the bars one standard deviation from the mean. Vertical dashed lines delineate grain categories based on Wentworth $(\mathrm{gr}=$ gravel, $\mathrm{g}=$ granules, $\mathrm{vc}=$ very coarse sand, $\mathrm{c}=$ coarse sand, $\mathrm{m}=$ medium sand, $\mathrm{f}=$ fine sand, and $\mathrm{vf}=\mathrm{very}$ fine sand). Horizontal black lines separate depositional units, based on field observation. Arrows show direction of vertical fining, if any, based on field observations. For reference, the grain size profile of beach sand collected in January is overlaid at the base of each section.

Nevertheless, as with more seaward areas, most of the trees in this region were snapped off near the ground. Current indicators showing seaward directed flow also appear here (Fig. 3, T12).

The tsunami deposit along the transect is a pinkish gray (5YR 7/2) poorly sorted coarse to very coarse sand, becoming medium sand landward. The gravel-sized grains are a mixture of rounded soil balls, angular coral fragments, concrete fragments, and rounded lithics from the Lho'nga Formation. Sand grains are a roughly equal mix of angular shell fragments and subangular siliciclastic mineral grains. The finest fraction appears have a higher concentration of mineral grains. The high carbonate ratio is borne out in the sediment density $\left(2.73 \mathrm{~g} / \mathrm{cm}^{3}\right)$, which is more consistent with calcite than with quartz.

The sand sheet is thin or absent along the shoreline, thickens to its "typical" thickness over $\sim 50 \mathrm{~m}$, then thins again abruptly near the landward limit (Fig. 4). Over the area where thickness varies least, change in thickness tends to correlate to small changes in topography-the overall effect is that small, pre-tsunami depressions are selectively filled in with sediment.

The sand sheet variously contains one, two, or three layers. These often appear normally graded or massive in the field (Fig. 3). Near the landward limit of deposition, however, the sheet consists of multiple couplets of sand overlain by muddy soil (Fig. 3, T13). The main sedimentary structure is normal grading, and plane lamination is visible in some sections (e.g. Fig. 3, T7). Only one section (T8, $220 \mathrm{~m}$ from shore), contained possible crossstratification. Many sections had a friable cap up to about 1 $\mathrm{cm}$ thick composed of sand similar to that below. This suggests that the cap might result from weak salt cement rather than from inclusion of finer grains. 


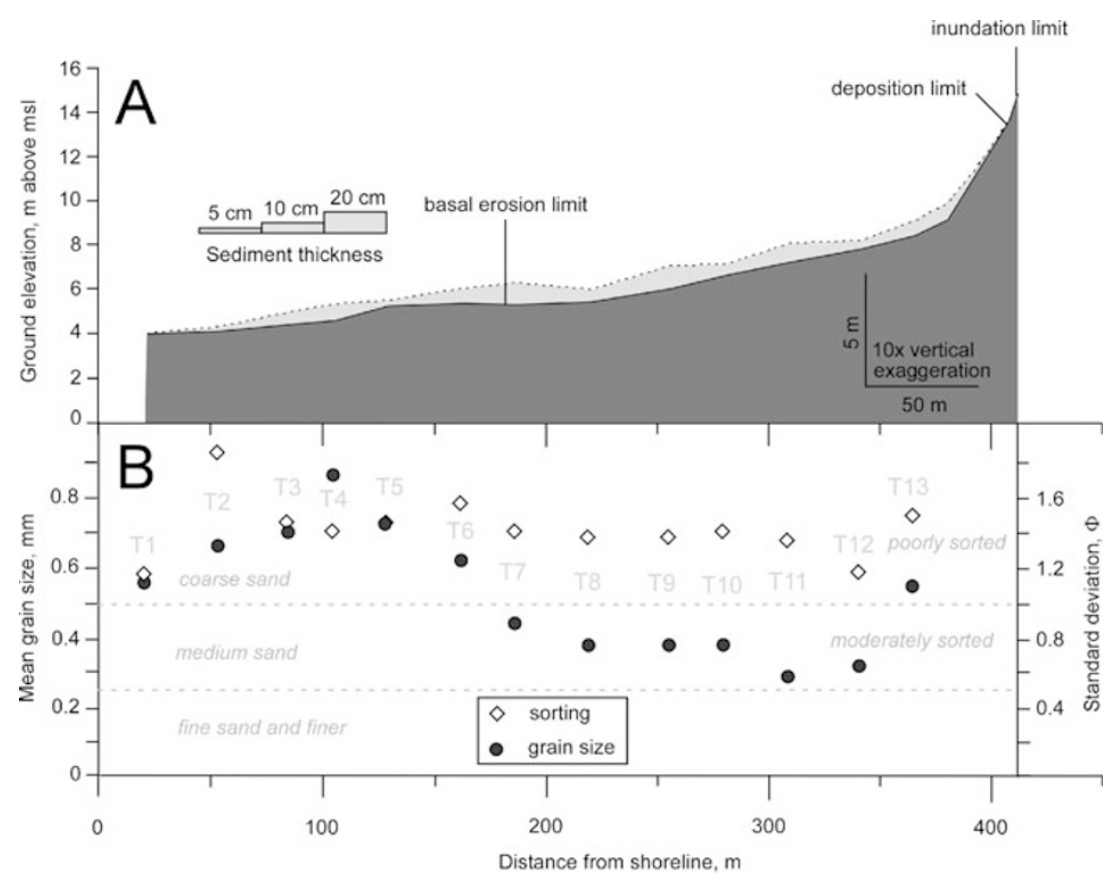

Fig. 4. A. Tsunami sediment thickness along the transect. The pre-tsunami surface is vertically exaggerated by $10 \times$; the thickness is exaggerated by $50 \times$ to allow small changes in thickness to be visible. B. Mean grain size of the lowest depositional unit in the sand along the transect. Where more than one sample was taken from the lowest unit (e.g. T6), the mean is based on moment analysis of a weighted average of the samples.

Although grain size analysis of the sediments along the transect shows overall landward and upward fining (Figs. 3 and 4), the trend is complicated by the presence of more than one dominant grain-size mode. The first dominant mode begins at the base of the shoreward deposit as a coarse sand peak, but shifts landward and upward to medium or medium-fine sand in the landward pits. The coarse sand is generally indistinguishable from beach sand collected from the shore in January 2005 (Fig. 3); the presence of unabraded Dentalium shells in the finer sands suggests that these grains were removed from Dentalium's habitat, i.e. below the low tide line.

A second sand peak at about $3 \phi$ (the division between fine and very fine sand) does not appear to shift with distance either vertically or laterally, but instead varies in prominence relative to the coarser peak. The peak first appears in basal T4 sediments $(\sim 110 \mathrm{~m}$ from shore $)$, but first becomes dominant in middle T6 sediments $(\sim 170 \mathrm{~m}$ from shore). We do not know the source of these sands; their increased presence in the deposit upward and landward raises the possibility that some sediment source was progressively "mined" by the advancing flow. Equally, in the landward sites, high proportions of the fine peak are associated with browner layers in the deposit; perhaps the fine peak source is soil stripped from the erosion zone.

Overall, the deposition and erosion pattern along the transect is consistent with an erosive pulse of water moving landward, followed by a quasi steady-state flow that slowly decelerates. During the accelerative phase, the seaward part of the transect was eroded, but acceleration at the front of the wave was insufficient to erode soil at the landward end of the transect. During the decelerating portion of flow, sediment was deposited where flow velocities at the bed were low enough to allow for deposition. Where flow veloci- ties remained high longer, such as along the seaward edge of the transect, little sediment was deposited until the flow waned. Repetition of this process allowed each successive wave to erode previous deposition along the seaward part of the transect. We do not currently fully understand the source of the sediment in the deposit, but hope to be able to use not only thickness and grain size trends within the deposit, but also a closer evaluation of potential source areas for the sediment, to better understand the processes by which sediment was deposited here.

\section{Summary}

Along a 450-meter-long transect of sediments deposited by the 2004 Sumatra-Andaman tsunami near Lhoknga, Indonesia, little sediment was deposited in the first $\sim 50 \mathrm{~m}$ from shore, where instead soil stripping and denuded tree trunks attest to scour. From 50 to 100 meters, the sand appears to thicken progressively, becoming 10 to $20 \mathrm{~cm}$ thick until $\sim 375 \mathrm{~m}$ from shore, where it thins abruptly to pinch out against a hillside about $400 \mathrm{~m}$ from shore.

The sand shows evidence of having multiple sources, including a source near the present shoreface, a subtidal source, and possibly an inland source. Sand appears to have been carried in suspension by the waves; sedimentary structures indicative of bedload transport are scarce or absent. Overall, the grain size fines both inland and upwards in the sand, but this picture is complicated by at least 3 pulses of sedimentation in the vertical, each of which may fine or coarsen.

Acknowledgments. Our colleagues on the International Tsunami Survey Team, particularly Alphonso, Hideo Matsutomi, Yoshikane Murakami, Sindhu Nugroho, Tsutomu Sakakiyama, Inyoman Sukanta, Yuichiro Tanioka, Yoshinobu Tsuji, Budi 
Waluyu, and Yudhicara, helped make our field work possible. Raphael Paris and Franck Lavigne also helped us during our fieldwork, and Stephen Woodward assisted with grain size analysis. Panlima Hasan, the owner of the Seaside Resort Hotel, allowed us to use his property during a very difficult time. The research was supported, in part, by the United States Geological Survey, the Kent State University Research Council, and Japan's Ministry of Education, Science, Sports and Culture, Grant-in-Aid for Special Purposes, 16800055, 2004.

\section{References}

Atwater, B. F., S. Musumi-Rokkaku, K. Satake, Y. Tsuji, K. Ueda, and D. K. Yamaguchi, The orphan tsunami of 1700-Japanese clues to a parent earthquake in North America, U.S. Geological Survey professional Paper 1707, 133, 2005.

Bennett, J. D., D. M. Bridge, N. R. Cameron, A. Djunuddin, S. A. Ghazali, D. H. Jeffery, W. Keats, N. M. S. Rock, S. J. Thompson, and R. Whandoyo, Geologic map of the Banda Aceh quadrangle, North Sumatra, Bandung, Indonesia, Geological Research and Development Centre, 1980.

Cisternas, M., B. F. Atwater, F. Torrejón, Y. Sawai, G. Machuca, M. Lagos, A. Eipert, C. Youlton, I. Salgado, T. Kamataki, M. Shishikura, C. P. Rajendran, J. K. Malik, Y. Rizal, and M. Husni, Predecessors of the 1960 giant Chile earthquake, Nature, 437, 404-407, 2005.

Dawson, A. G., S. Shi, S. Dawson, T. Takahashi, and N. Shuto, Coastal sedimentation associated with the June 2nd and 3rd, 1994 tsunami in Rajegwesi, Java, Quaternary Science Reviews, 15, 901-912, 1996.

Gelfenbaum, G. and B. Jaffe, Erosion and sedimentation from the 17 July, 1998 Papua New Guinea Tsunami, Pure and Applied Geophysics, 160, 1969-1999, 2003.

Hamzah, L., N. T. Puspito, and F. Imamura, Tsunami catalog and zones in Indonesia, Journal of Natural Disaster Science, 22, 25-43, 2000.

Kamataki, T and Y. Nishimura, Field Survey of the 2004 Off-Sumatra earthquake tsunami around the Banda Aceh, Northern Sumatra, Indonesia, Journal of Geography, 114, 78-82, 2005 (in Japanese).

Konno, E. (ed.), Geological observations of the Sanriku coastal region damaged by tsunami due to the Chile earthquake in 1960, Contributions to the Institute of Geology and Paleontology, Tohoku University, 52,
$1-40,1961$.

Minoura, K., F. Imamura, T. Takahashi, and N. Shuto, Sequence of sedimentation processes caused by the 1992 Flores tsunami, Geology, 25, 523-526, 1997.

Nanayama, F., K. Satake, R. Furukawa, K. Shimokawa, B. F. Atwater, K. Shigeno, and S. Yamaki, Unusually large earthquakes inferred from tsunami deposits along the Kuril trench, Nature, 424, 660-663, 2003.

Nishimura, Y. and N. Miyaji, Tsunami deposits from the 1993 Southwest Hokkaido earthquake and the 1640 Hokkaido Komagatake eruption, Northern Japan, in Tsunamis: 1992-1994, Their Generation, Dynamics, and Hazard, edited by K. Satake and F. Imamura, pp. 719-734, Basel, Birkhäuser, 1995.

Pinegina, T. K., J. Bourgeois, L. I. Bazanova, I. V. Melekestsev, and O. A. Braitseva, A millennial-scale record of Holocene tsunamis on the Kronotskiy Bay coast, Kamchatka, Russia, Quaternary Research, 59, 36-47, 2003.

Sato, H., T. Shimamoto, A. Tsutsumi, and E. Kawamoto, Onshore tsunami deposits caused by the 1993 Southwest Hokkaido and 1983 Japan Sea earthquakes, in Tsunamis: 1992-1994, Their Generation, Dynamics, and Hazard, edited by K. Satake and F. Imamura, pp. 693-717, Basel, Birkhauser, 1995.

Shi, S., A. G. Dawson, and D. E. Smith, Coastal sedimentation associated with the December 12th, 1992 tsunami in Flores, Indonesia, in Tsunamis: 1992-1994, Their Generation, Dynamics, and Hazard, edited by K. Satake and F. Imamura, pp. 525-536, Basel, Birkhauser, 1995.

Tanioka, Y., Yudhicara, T. Kusunose, S. Kathiroli, Y. Nishimura, S. Iwasaki, and K. Satake, Rupture process of the 2004 great SumatraAndaman earthquake estimated from tsunami waveforms, Earth Planets Space, 58, this issue, 203-209, 2006.

Wright, C. and A. Mella, Modifications to the soil pattern of south-central Chile resulting from seismic and associated phenomena during the period May to August 1960, Bulletin of the Seismological Society of America, 53, 1367-1402, 1963.

A. Moore (e-mail: amoore5@kent.edu), Y. Nishimura, G. Gelfenbaum, T. Kamataki, and R. Triyono 